stratigraphical distortions; and, second, their records are well-dated and are correlated directly with similar climatic evidence drawn from the Greenland Dye-3 ice core. The dramatic short-term climatic oscillations documented in the ice core $^{8}$ affected the regional climates all the way over to Northwest Europe.

The combined deep-ocean oxygen and carbon isotope data shown by Veum et al. imply that large parts of today's subpolar North Atlantic froze over during the Younger Dryas. The forming sea ice rejects salt, so increasing surfacewater salinity, which apparently resulted in a density flux large enough to ventilate the deeper water column at least as effectively as today. Clearly, this evidence must be confirmed. If the data can be reproduced at other coring locations and still show that open-ocean convection occurred even during the coldest periods of the Younger Dryas - when the conveyor belt was supposedly switched off - climate modellers will have to deal not only with the ons and offs of the conveyor but possibly also with switches between cold and warm conveyors. The correlation of core data from the Norwegian-Greenland Sea with those from the shallow North Atlantic seems to imply that during the Younger Dryas the cold conveyor belt operated at shallower depth than today's warm belt. The driving force behind the cold belt would be a gradual buildup of salinity during sea-surface freezing, which would resemble the mechanism which starts off deep convection in today's Southern Ocean ${ }^{\text {. }}$. This factor is not accounted for by the concept of salt transport through heat and vapour flux $x^{4,5}$ and, frankly, it sounds rather far-fetched. Yet the data exist and must be confronted.

An obvious shortcoming of the conveyor-belt/salt-flux hypothesis is that it deals with mean-ocean conditions and North-Atlantic mean flow rates. Thermohaline circulation is driven by regional and seasonal anomalies in the ocean's temperature-salinity field. The main sites of convection which feed today's conveyor belt are located in very restricted areas in the NorwegianGreenland Seas and the Labrador Sea. In these areas convection occurs mainly during winter time. One may argue that this dependency on sinking of water masses in restricted provinces would make the conveyor belt even more vulnerable to large-scale meltwater input. Still, it seems that even during times of highest meltwater input immediately before and after the Younger Dryas, the deep North Atlantic was better ventilated than during the Younger Dryas ${ }^{10}$, which may have been meltwater-free ${ }^{6}$.

It seems critical to finding a solution for this circulation puzzle to determine

\title{
Chronology of Younger Dryas research
}

LATE 1970 s Dominance of polar foraminiferal populations implies TO nearly full-glacial conditions during the Younger EARLY ' 80 s Dryas which may be caused by rapid meltwater injection during the initial disintegration of continental ice sheets ${ }^{15.16}$

1987

NOVEMBER Geochemical evidence arises for extremely low ventilation of the deep North Atlantic during the Younger Dryas, implying a shut-down of water-mass sinking in the North Atlantic and a halt of the conveyor belt ${ }^{10}$.

1988

FEBRUARY Meltwater signals in sediment cores from the Gulf of Mexico and the subarctic North Atlantic imply a diversion of meltwater flow from the Gulf to the North Atlantic before and during the Younger Dryas. Poleward flow of warm waters in the conveyor belt was cut off causing the Younger Dryas climatic collapse around the North Atlantic ${ }^{3}$.

OCTOBER Stable isotope and planktonic faunal records from a Northwest Pacific sediment core show a cooling event synchronous with the Younger Dryas. The data suggest that the Younger Dryas was not restricted to the North Atlantic and that the cooling took in the high-latitude North Pacific ${ }^{17}$.

1989

MAY

A drop in North Atlantic surface water temperature by almost $10^{\circ} \mathrm{C}$ during the Younger Dryas is indicated by changes in the planktonic community structure ${ }^{18}$ and seems to be consistent with a conveyor-belt switch-off mode.

JUNE Geochemical tracers and airborne dust embedded in Greenland ice layers show the North Atlantic climate shifted 'back to normal' in less than 20 years at the end of the Younger Dryas ${ }^{8}$.

DECEMBER Growth rate curves of reef corals off Barbados point to strongly reduced meltwater inputs to the North Atlantic during the Younger Dryas. The hypothesis that increased meltwater discharge into the North Atlantic is the cause of the Younger Dryas comes under fire ${ }^{6,19}$

1990

FEBRUARY Benthic and planktonic isotope data from a northeast Atlantic sediment core imply increased deep water formation and ventilation of the deeper water column during the Younger Dryas, further undermining the meltwater hypothesis ${ }^{7}$

AUGUST

In a revision of the meltwater hypothesis, a salt oscillator is designed which turns the conveyor belt on and off. The strength of the conveyor belt no longer depends on the rate of deglacial meltwater input, as the primary force is now heat flux and vapour transport ${ }^{4}$

DECEMBER Numerical modelling of the salt oscillator suggests that North Atlantic surface salinity may fluctuate at periods of a few thousand years. The model does not test the sensitivity of salt oscillations to regionally variable meltwater inputs ${ }^{5}$.

Long time series of benthic isotope records show Younger-Dryas type climatic reversals during six deglacial transitions of the past 700,000 years. Each was supposedly accompanied by a temporary shutdown of deep-water production in the North Atlantic pointing to a switch-off of the conveyor belt ${ }^{13}$.

Pollen records from southeastern Alaska document a cooling event which may have been coeval with the Younger Dryas; the Younger Dryas was a possibly hemisphere-wide event ${ }^{20}$.

1991

JANUARY Deglacial climate breakdowns are observed in isotope records from two Sulu Sea sediment cores and are used to infer that the Younger Dryas was a global event caused by lowered atmospheric $\mathrm{CO}_{2}$ concentrations ${ }^{21}$.

SEPTEMBER High-resolution palaeochemical records from the North Atlantic reveal periodic decreases in deepwater production during deglaciation at roughly the same periods as predicted from the salt-oscillation model. Decreased ventilation of the deeper water column during the Younger Dryas suggests the conveyor belt was switched off as North Atlantic surface salinities decreased, owing to meltwater input or cooling ${ }^{22}$

1992

JANUARY Comparison of geochemical records obtained from North Atlantic and Southern Ocean sediment cores implies a significant influx of North Atlantic water masses to the Southern Ocean even during the Younger Dryas ${ }^{11}$ - the conveyor belt remained switched on.

APRIL High-resolution geochemical and plankton data imply a rapid shut-down of circulation during the Younger Dryas in the North Atlantic ${ }^{1}$, but benthic isotope data from the same region suggest that deep ventilation continued and was probably as vigorous as today ${ }^{2}$. 